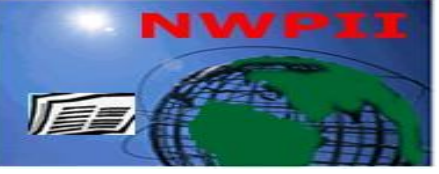

American Journal of Biomedical Sciences

ISSN: 1937-9080

nwpii.com/ajbms

\title{
Cardiopulmonary Bypass Surgery in Children: Minimizing the Incidence of Postoperative Junctional Ectopic Tachycardia after Surgical Technique Modification
}

\author{
Ahmad Saeed Azhar ${ }^{*}$ \\ Pediatric Department, Faculty of Medicine, King Abdul Aziz University, Jeddah, Saudi Arabia \\ *Corresponding author: \\ Ahmad Saeed Azhar \\ Consultant Pediatric Cardiologist, MBBS, FRCPC \\ Assistant Professor, \\ Pediatric Department \\ Faculty of Medicine \\ King Abdul aziz University \\ Jeddah, Saudi Arabia \\ Cell \# 00966555540500 \\ Fax \# 0096626079292 \\ Email: azcardio@hotmail.com \\ ahmad_azhar63@yahoo.com
}

Received: 16 December 2010; | Revised: 27 November 2011; | Accepted: 2 December 2011

\begin{abstract}
Background: Mechanical injury to tissues in and surrounding the Atrioventricular node is considered a major factor in the aetiology of postoperative Junctional Ectopic Tachycardia (JET).

Objectives: The study aims to evaluate the effect of retractor modification used during cardiopulmonary bypass surgery and the incidence of postoperative JET in children.

Material \& Methods: The study involves retrospective chart review of all pediatric patients who had undergone cardiopulmonary bypass surgery in Children Hospital of Eastern Ontario, Canada, between 1993 and 1996. Patients treated between 1993 to 1994 with wide eyelid retractor (depth 23mm; width $18 \mathrm{~mm}$ ) were classified as Group A, and the patients treated with narrow retractor (depth $10 \mathrm{~mm}$; width $8 \mathrm{~mm}$ ) between 1995 to 1996 were classified as Group B, respectively.

Results: Of the study subjects, Group A had 209 while Group B had 186 subjects. The age and weight of group A subjects was "mean \pm standard deviation" (4.4 \pm 4.1 year and $17 \pm 12 \mathrm{~kg}$ ), while that of Group B was $(4.7 \pm 4.7$ year and $20 \pm 15 \mathrm{~kg})$. The overall incidence of postoperative JET and mortality was lower in Group B than Group A (2\% vs. 10\%; $\mathrm{p}=0.0008 ; 0 \%$ vs. $21 \%$; $\mathrm{p}<0.05$, respectively).

Conclusion: A decrease in the incidence of JET and mortality was noticed after the use of narrow retractor.
\end{abstract}

Keywords: JET, Retractor, Cardiopulmonary, Bypass, Surgery. 


\section{Introduction}

Junctional Ectopic Tachycardia (JET) is relatively a malignant arrhythmia but infrequently reported in spontaneous congenital form (1) while its frequent incidence was reported after surgical correction of congenital heart defects (2-7). Its aggressive management is mandatory because of the probability of substantial morbidity. The lack of atrioventricular synchrony and the high ventricular rate may lead to diminished cardiac output, which may in turn lead to increase adrenergic tone, further accelerating the heart rate $(2,8)$.

Careful medical and nursing support makes JET a self-limiting disorder that usually resolves in 2 to 8 days. Intensive care characteristically includes surface cooling, atrial pacing, and antiarrhythmic rate-control therapy $(3,6)$. Although catecholamines may worsen the tachyarrhythmia, such inotropes are commonly used to support the circulation.

JET has been reported after the repair of every type of cardiac anomaly, but it is most often observed after correction of Tetralogy of Fallot (TOF) and surgical intervention in proximity to the atrioventricular node and the bundle of His, i.e. operations that include closure of ventricular septal defect (VSD) (7).

It is postulated that disruption of conduction tissue, by either direct trauma or penetrating blood and interstitial inflammatory cells, may result in an irritable focus leading to JET (8).

The purpose of this study was to ascertain the association of intra-operative modified surgical technique by using straight narrow retractor with development of JET in the immediate postoperative period for cardiopulmonary bypass surgery.

\section{Materials and Methods}

This study represented a retrospective chart review of all children who underwent cardiopulmonary bypass surgery for congenital heart disease at the Children Hospital of Eastern Ontario "A Single Surgeon Institution" between January 1993 and December 1996.
The Patients were divided into two groups, i.e. Group A "who underwent open heart surgery between January 1993 and December 1994", and Group B "who underwent surgery between January 1995 and December 1996".

In our settings, the diagnostic criteria for JET include the following:

(1) Narrow QRS tachycardia in the absence of surgically induced right bundle branch block.

(2) A rate between 170 and 230 beats/min or greater than the 98th percentile for age.

(3) Atrioventricular dissociation with hemodynamic repercussion, and

(4) Aventricular rate faster than the atrial rate.

The primary outcome variable was the occurrence of JET, as manifested on the postoperative 12-lead ECG. When available, an atrial-lead ECG will be obtained with the temporary epicardial pacing wires to use as an adjunct to the diagnosis. The postoperative period was defined up to 30 days after operation or hospital discharge, whichever was the earliest.

A single surgeon applied a similar surgical technique by using wide eyelid retractor between January 1993 and December 1994, and in January 1995, a surgical modification was applied. This modification was basically a change of the retractor used to retract the tricuspid valve leaflets during the exposure of the ventricular septal defect from a wide eyelid retractor "Depth 23m ; width $18 \mathrm{~mm}$ " to a straight narrow retractor "depth $10 \mathrm{~mm}$; width $8 \mathrm{~mm}$ ". Special attention was made to minimize excessive retraction on the edges of the tricuspid leaflets and tissues close to the AV node and Bundle of His.

The treated cases included: TOF, transposition of great arteries (TGA), ventricle septal defect (VSD), atrial septal defects (ASD), atrioventricular septal defect (AVSD), and complex cyanotic congenital heart diseases.

The data collection was based on patient charts, cardiac intensive care unit (CICU) records, and 12-lead surface or atrial electrocardiograms (ECG). The data included the preoperative factors, intra-operative and postoperative factors. The preoperative factors included age, weight, and diagnosis while intra-operative factors included type of surgical procedure, cross clamp time, 
cardiopulmonary bypass time and the need for inotropic support after coming off pump.

The post operative factors included hypotension (defined as blood pressure less than two standard deviations from the mean), postoperative renal failure (defined as the need for peritoneal or hemodialysis), electrolytes $(\mathrm{Na}+1$ $\mathrm{Ca}+2 / \mathrm{K}+/ \mathrm{Mg}+2)$ and acid-base disturbances, heart block or the need for a temporarily pacemaker, and type and dosage of inotropic medication.

Pediatric age group was taken upto18 years.

\subsection{Statistical analysis}

The data were analyzed using SPSS version 10 (SPSS Inc., Chicago, IL, USA) and subjected to descriptive analysis. Continuous data were subjected for normality by Kolmogrove Simirnove test. Continuous values were expressed as median (1st and 3rd quartile).

Categorical data were analyzed as frequency and percentage. Frequency data were subjected to modified Wald method to measure $95 \%$ Confidence Interval (CI) of proportion, Fisher's exact test and Chi square test. The nonparametric continuous data was analysed by the Wilcoxon Rank Sum test. A two tailed $\alpha$ level of $<0.05$ was considered significant.

\subsection{Ethical issues}

The study was presented in detailed with its intended purpose and was approved by the Institutional Review Board and the Ethical Approval Committee. We declare that we have no financial and/or personal relationship(s), which may have inappropriately influenced us in writing this paper.

\section{Results}

The analysis consisted of data from 209 patients in group A and 186 patients in Group B. The (mean \pm Standard Deviation) of age and weight of group A subjects was $(4.4 \pm 4.1$ year and $17 \pm 12 \mathrm{~kg})$ while that of Group B was $(4.7 \pm 4.7$ year and $20 \pm 15 \mathrm{~kg}$ ).

Table 1, Subjects' Frequency With Postoperative Junctional Ectopic Tachycardia (JET)

\begin{tabular}{|c|c|c|c|c|c|c|c|}
\hline \multirow{2}{*}{ Variables } & \multicolumn{3}{|c|}{ Group A (n=209) } & \multicolumn{3}{c|}{ Group B (n=186) } & \multirow{2}{*}{ p-Value§ } \\
\cline { 2 - 7 } & $\mathrm{no}^{*}$ & $\%$ & $95 \% \mathrm{CI} \dagger$ & $\mathrm{no}{ }^{*}$ & $\%$ & $95 \% \mathrm{CI} \dagger$ & \\
\hline TOF & $9 / 31$ & 29 & $0.16-0.47$ & $4 / 23$ & 17.4 & $0.06-0.38$ & 0.3580 \\
\hline Shunt & $5 / 138$ & 3.6 & $0.01-0.08$ & $0 / 111$ & 0 & $0.00-0.04$ & 0.0673 \\
\hline Lesions & & & & & & & 0.4805 \\
\hline TGA & $2 / 12$ & 16.7 & $0.04-0.46$ & $0 / 10$ & 0 & $0.00-0.32$ & 0.0029 \\
\hline Others & $6 / 28$ & 21.4 & $0.09-0.39$ & $0 / 42$ & 0 & $0.00-0.09$ & \\
\hline Overall & $22 / 209$ & 10.5 & $0.07-0.15$ & $4 / 186$ & 2.2 & $0.006-0.06$ & 0.0008 \\
\hline
\end{tabular}

TOF=Fallots of Tetrology

Shunt Lesions= atrial septal defects, ventricular septal defects, and atrioventricular septal defects.

TGA=Transposition of great arteries

Others $=$ complex cyanotic congenital heart disease

*no of subjects with JET/Total subjects operated

$\uparrow 95$ percent Confidence Interval

$\S$ Fisher's Exact Test 
The overall incidence of postoperative JET and mortality was lower in Group B than Group A ( $2 \%$ vs. $10 \% ; \mathrm{p}=0.0008 ; 0 \%$ vs. $21 \% ; \mathrm{p}<0.05$, respectively). All patients experienced JET in immediate postoperative period (24hours) in both groups. However, no patient had JET documented greater than one week. The distribution of cases based on clinical diagnosis were the same during the two study periods but majority of JET were seen in the TOF cases in both groups, Group A, 9 (40.9\%), Group B, 4 (100\%). (Table1).

No significant differences in the studied variables were found between group $\mathrm{A}$ and $\mathrm{B}$, respectively. (Table 2)

\begin{tabular}{|l|c|c|c|}
\hline \multicolumn{4}{|l|}{ Table 2, Clinical Profile of subjects: Pre, intra, and postoperative findings } \\
\hline Variables & Group A (n=209) & Group B (n=186) & P value \\
\hline Age (years) & $2.9(1.3,6)$ & $3(1,7)$ & 0.96 \\
\hline weight (Kg) & $14(8.2,23.3)$ & $14(8,28)$ & 0.88 \\
\hline Cardiopulmonary bypass time (min) & $233(86,401)$ & $255(95,425)$ & 0.21 \\
\hline Cross clamp time (min) & $90(30,214)$ & $93(48,228)$ & 0.12 \\
\hline Dopamine (microgram/kg/min) & $10(5,10)$ & $10(5,10)$ & 0.33 \\
\hline Amiodarone (microgram/kg/min) & $10(5,10)$ & $10(5,10)$ & 0.91 \\
\hline Dobutamine (microgram/kg/min) & $9(5,10)$ & $10(5,10)$ & 0.82 \\
\hline Hypotension ${ }^{\beta}$ & $30(14.4)$ & $24(12.9)$ & 0.67 \\
\hline Renal failure ${ }^{\beta}$ & $17(8.1)$ & $13(7)$ & 0.668 \\
\hline Heart block ${ }^{\beta}$ & $39(18.7)$ & $31(16.7)$ & 0.60 \\
\hline pH & $7.39(7.38,7.43)$ & $7.39(7.37,7.43)$ & 0.89 \\
\hline Magnesium (mmole/L) & $0.88(0.79,0.95)$ & $0.9(0.83,0.97)$ & 0.75 \\
\hline
\end{tabular}

${ }^{\beta} \mathrm{n}(\%)$, chi-square test

All other have median (1st and 3rd quartiles), Wilcoxon Rank-Sum test

\section{Discussion}

Regardless of deficient in knowledge with reference to the cellular or macroscopic cause of JET, the presence of arrhythmia in the postoperative period is viewed as a marker of untoward effects of the surgical procedure. In former reports, the cause of JET is thought to be a result of a combination of factors, including underlying heart disease, type of surgical 
procedure, hemodynamic instability, and electrolyte imbalance, namely hypomagnesemia (9-16). Yet, mechanical trauma to conduction tissue in and around the AV node and bundle of his resulting in an irritable focus has been postulated by many authors as a significant contributing factor $(8,17)$. However, JET was still noted in some patients who did not undergo operations near the atrioventricular node or intracardiac surgical procedure. Additionally, there was also no association found between electrolyte disturbances and JET within 72 hours after operation (18).

In our study, all patients experienced JET in the immediate postoperative period as well as no patient had JET greater than 1 week contrary to that of Hoffman findings, i.e. (range 1 to 50 days; median, 1 day) and 3 patients experienced JET greater than one week (18). Incidence of postoperative JET decreased from $10 \%$ to $2 \%$ with a close temporal association of a modification in surgical technique in our study. The recorded incidence of postoperative JET was approximately 5 to $12 \%$ (19). Our study had shown no significant difference between the groups about known clinical or biochemical variable associated with the cardiopulmonary bypass or postoperative care. Furthermore, these findings support the mechanical trauma as a considerable factor contributing to the development of postoperative JET.

Our study showed $50 \%$ of patients who developed postoperative JET in both groups, underwent surgical repair for (TOF), was consistent with previously reported findings (20, 21). The mortality rate from postoperative JET in this study was $21 \%$, consistent with that previously reported and better than that in the initial reports of this rhythm disturbance (23). Postoperative care is directed to increase vagal tone, decrease sympathetic tone, normalization of metabolic status and optimizing cardiac output (2, 22).

Therefore, our observation supported previous hypotheses of the role of mechanical trauma in developing postoperative JET and emphasized the importance of careful intra-operative handling of juxta nodal tissues with the use of small retractors and surgical instruments with optimal exposure of the surgical site.

\section{Conclusion}

In summary, 22 (10\%) out of 209 patients who underwent cardiac surgical procedure with wide eyelid retractor developed JET as compared to $4(2 \%)$ of 186 patients who underwent cardiac surgery by narrow retractor, in our institution.

Former group had $21 \%$ mortality as compared to afterward $(0 \%)$. It may be speculated that straight narrow retractor should be used for cardiopulmonary bypass surgical procedures for congenital heart diseases.

\section{Acknowledgement}

The author thanks Dr. Walter J Duncan and Dr. Gary Cornel for their guidance and valuable contributions.

\section{References}

1. Villain E, Vetter V, Garcia JM, Herre J, Cifarelli A, Garson A Jr. Evolving concepts in the management of congenital junctional ectopic tachycardia. Circulation. 1990;81(5):1544-9. doi:10.1161/01.CIR.81.5.1544

2. Gillette PC. Diagnosis and management of postoperative junctional ectopic tachycardia. Am Heart J. 1989;118(1):192-4. doi: $\underline{\text { 10.1016/0002-8703(89)90098-7 }}$

3. Balaji S, Sullivan I, Deanfield J, James I. Moderate hypothermia in the management of resistant automatic tachycardias in children. $\mathrm{Br}$ Heart J. 1991;66(3):221-4. doi:10.1136/hrt. $\underline{66.3 .221}$

4. Till JA, Rowland E. Atrial pacing as an adjunct to the management of post-surgical His bundle tachycardia. Br Heart J. 1991;66(3):225-9. doi:10.1136/hrt.66.3.225

5. Raja P, Hawker RE, Chaikitpinyo A, Cooper SG, Lau KC, Nunn GR, et al. Amiodarone management of junctional ectopic tachycardia after cardiac surgery in children. Br Heart J. 1994;72(3):261-5. doi:10.1136/hrt.72.3.261 
6. Pfammatter JP, Paul T, Ziemer G, Kallfelz HC. Successful management of junctional tachycardia by hypothermia after cardiac operations in infants. Ann Thorac Surg. 1995;60(3):556-60. doi:10.1016/00034975(95)00425-K

7. Walsh EP, Saul P, Sholler GF, Triedman JK, Jonas RA, Mayer JE. Evaluation of a staged treatment protocol for rapid automatic junctional ectopic tachycardia after operation for congenital heart disease. J Am Coll Cardiol. 1997;29(5):1046-53. doi:10.1016/S07351097(97)00040-5

8. Till JA, Ho SY, Rowland E. Histopathological findings in three children with His bundle tachycardia occurring subsequent to cardiac surgery. Eur Heart J. 1992;13(5):709-12.

9. Dietl CA, Cazzaniga ME, Dubner SJ, PerezBalino JA, Torres AR, Favaloro RG. Lifethreatening arrhythmias and RV dysfunction after surgical repair of tetralogy of Fallot. Comparison between transventricular and transatrial approaches. Circulation 1994;90(5 Pt 2):II7-12.

10. Parry AJ, McElhinney DB, Kung GC, Reddy VM, Brook MM, Hanley FL. Elective primary repair of acyanotic tetralogy of Fallot in early infancy: overall outcome and impact on the pulmonary valve. J Am Coll Cardiol 2000;36(7):2279-83. doi:10.1016/S07351097(00)00989-X

11. Ziemer PT, Luhmer G, Bertram H, Hecker H, Kallfelz HC. Early and late atrial dysrhythmias after modified Fontan operation. Pediatr Med Chir 1998;20(1):9-11.

12. Amodeo A, Galletti L, Marianeschi S, Picardo S, Giannico S, Di Renzi P, et al. Extracardiac Fontan operation for complex cardiac anomalies: seven years' experience. J Thorac Cardiovasc Surg 1997;114(6):1020-30. doi:10.1016/S0022-5223(97)70016-3

13. Kaulitz R, Ziemer G, Luhmer I, Kallfelz HC. Modified Fontan operation in functionally univentricular hearts: preoperative risk factors and intermediate results. J Thorac Cardiovasc Surg 1996;112(3):658-64. doi:10.1016/S0022$\underline{\text { 5223(96)70049-1 }}$
14.Manning PB, Mayer JE, Wernovsky G, Fishberger SB, Walsh EP. Staged operation to Fontan increases the incidence of sinoatrial node dysfunction. J Thorac Cardiovasc Surg 1996; 111(4):833-9. doi:10.1016/S00225223(96)70344-6

15. Dodge-Khatami A, Miller OI, Anderson RH, Goldman AP, Gil-Jaurena JM, Elliott MJ, et al. Surgical substrates of postoperative junctional ectopic tachycardia in congenital heart defects. J Thorac Cardiovasc Surg 2002;123(4):624-30. doi: $10.1067 / \mathrm{mtc} .2002 .121046$

16. Dorman BH, Sade RM, Burnette JS, Wiles HB, Pinosky ML, Reeves ST, et al. Magnesium supplementation in the prevention of arrhythmias in pediatric patients undergoing surgery for congenital heart defects. Am Heart J 2000;139(3):522-8. doi:10.1016/S00028703(00)90097-8

17. Krongrad E. Postoperative arrhythmias in patients with congenital heart disease. Chest 1984; 85:107-13. doi:10.1378/chest.85.1.107

18. Hoffman TM, Bush DM, Wernovsky G, Cohen MI, Wieand TS, Gaynor JW, et al. Postoperative junctional ectopic tachycardia in children: incidence, risk factors, and treatment. Ann Thorac Surg. 2002;74(5):1607-11. doi:10.1016/S0003-4975(02)04014-6

19. Braunstein PW, Sade RM, Gillette PC. Life threatening postoperative junctional ectopic tachycardia. Ann Thorac Surg 1992; 53(4):7268. doi:10.1016/0003-4975(92)90348-8

20. Balaji S. Postoperative Cardiac Arrhythmias in Children. Curr Treat Options Cardiovasc Med. 2001 Oct; 3(5):385-92. doi:10.1007/s11936001-0028-3

21. Yildirim SV, Tokel K, Saygili B, Varan B. The incidence and risk factors of arrhythmias in the early period after cardiac surgery in pediatric patients. Turk J Pediatr. 2008 Nov-Dec; 50(6): 549-53.

22. Case CL, Gillette PC. Automatic atrial and junctional tachycardias in the pediatric patient: Strategies for diagnosis and management. PACE. 1993;16:1323-35. doi:10.1111/j.15408159.1993.tb01719.x 